\title{
Review Article \\ The Application of Microfluidics in Preparing Nano Drug Delivery Systems
}

\author{
Tran Thi Hai Yen*, Dang Thuy Linh, Pham Thi Minh Hue \\ Hanoi University of Pharmacy, 13-15 Le Thanh Tong, Hoan Kiem, Hanoi, Vietnam
}

Received 28 February 2019

Revised 09 May 2019; Accepted 21 June 2019

\begin{abstract}
Microfluidics is an emerging and promising interdisciplinary technology which offers powerful platforms for precise production of novel functional materials (e.g., emulsion droplets, microcapsules, and nanoparticles as drug delivery vehicles) as well as high-throughput analyses (e.g., bioassays and diagnostics). Microfluidics has recently appeared as a new method of manufacturing nanostructures, which allows for reproducible mixing in miliseconds on the nanoliter scale. This review first describes the fundamentals of microfluidics and then introduces the recent advances in making nanostructures for pharmaceutical applications including nano liposomes, polymer nanoparticles and nano polymerosomes.
\end{abstract}

Keywords: Microfluidics, drug nanocarrier, nano liposomes, polymer nanoparticles, polymerosomes.

\footnotetext{
${ }^{*}$ Corresponding author.

Email address: tranyendhd@gmail.com
}

https://doi.org/10.25073/2588-1132/vnumps.4150 


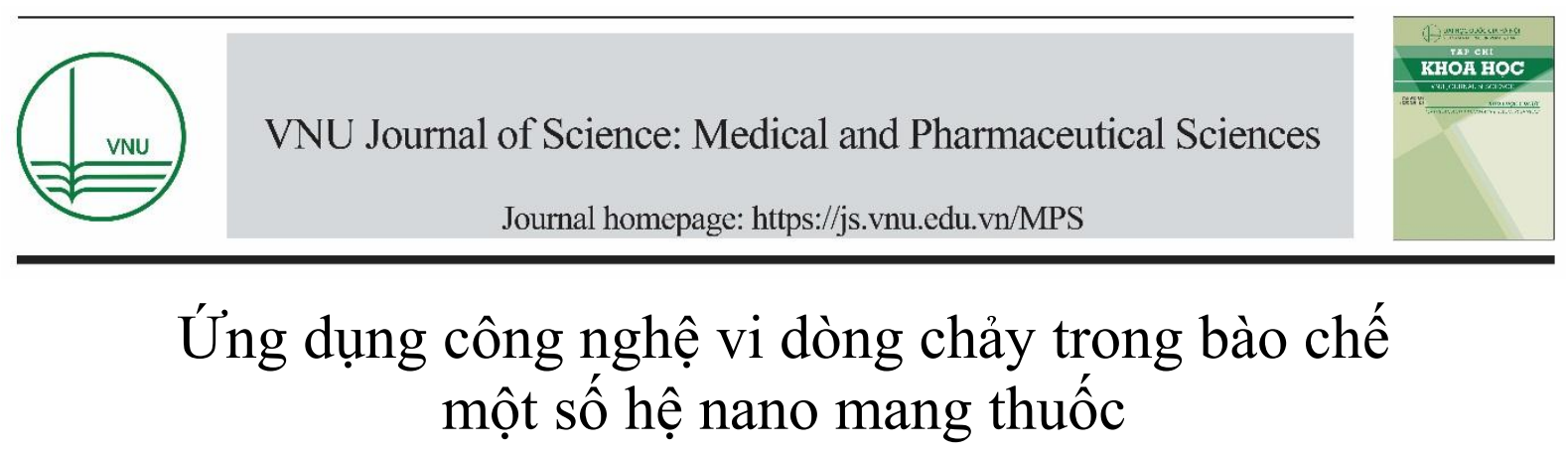

\author{
Trần Thị Hải Yến*, Đặng Thùy Linh, Phạm Thị Minh Huệ \\ Truoòng Đại Học Dược Hà Nội, 13-15 Lê Thánh Tông, Hoàn Kiếm, Hà Nội, Việt Nam \\ Nhận ngày 28 tháng 02 năm 2019 \\ Chỉnh sửa ngày 09 tháng 5 năm 2019; Chấp nhận đăng ngày 21 tháng 6 năm 2019
}

\begin{abstract}
Tóm tăt: Công nghệ vi dòng chảy là giải pháp kỹ thuật liên ngành có tiềm năng trong sản xuất chính xác các vật liệu mới (các hệ mang thuốc nhũ tương, vi nang, tiểu phân nano) cũng như các phép phân tích chính xác (như định lượng sinh học, chẩn đoán...). Công nghệ vi dòng chảy hiện nay được ứng dụng như là một phương pháp chế tạo các hệ cấu trúc nano, bởi nó có thể trộn các thể tích nano lit trong thời gian nano giây. Trong bài này, chúng tôi tổng quan về nguyên tắc của công nghệ vi dòng chảy trong bào chế các hệ có cấu trúc nano áp dụng trong dược học như nano liposome, tiểu phân nano polyme và polymerosome.
\end{abstract}

Tù khóa: Công nghệ vi dòng chảy, tiểu phân nano mang thuốc, nano liposome, tiểu phân nano polyme, polymerosome.

\section{Giới thiệu về công nghệ vi dòng chảy (Microfluidic)}

Vi dòng chảy là công nghệ thao tác và xử lý chất lỏng trong vi kênh - là các kênh có kích thước từ hàng chục đến hàng trăm micromet. Hệ thống các vi kênh có thể được hình dung giống như hệ thống các mạch máu nhỏ trong cơ thể, vì thế công nghệ này rất gần gũi với hướng phỏng sinh học trong y dược học [1]. Sự chuyển động của chất lỏng trong các kênh kích cỡ siêu nhỏ có những đặc tính độc đáo, mang lại nhiều ứng dụng trong các lĩnh vực khác nhau [2]. Hiện nay công nghệ vi dòng chảy được ứng dụng trong rất nhiều lĩnh vực như chế tạo vật liệu, $\mathrm{y}$ sinh như phản ứng sinh hóa, nuôi cấy tế bào ... Công nghệ vi dòng chảy còn được gọi với tên "lab on chip", có nghĩa là một phòng thí nghiệm tích hợp trong con chip nhỏ. Ngày nay rất nhiều nghiên cứu trên nhiều lĩnh vực ứng dụng công nghệ vi dòng chảy đã được công bố trên các tạp chí khoa học.

Các thiết bị vi dòng chảy không chỉ đơn giản là một phiên bản thu nhỏ của các bản sao ở tầm vĩ mồ vì sự chuyển động của chất lỏng ở quy mô cỡ micromet khá phức tạp, do có thể có vài hiện tượng diễn ra cùng một lúc. Do vậy thường sử

\footnotetext{
* Tác giả liên hệ.

Địa chỉ email: tranyendhd@gmail.com

https://doi.org/10.25073/2588-1132/vnumps.4150
} 
dụng các thông số để diễn tả một số quá trình xảy ra chủ yếu, một trong những thông số được quan tâm nhất là chỉ số Reynolds (Re). Trong cơ học chất lỏng, chỉ số Reynolds là một giá trị không thứ nguyên biểu thị độ lớn tương đối giữa ảnh hưởng gây bởi lực quán tính và lực ma sát (tính nhớt) lên dòng chảy. Sự chuyển tiếp của chỉ số Re nói chung trong khoảng 1500-2500 mang lại những sự khác biệt về thủy động học của dòng chảy. Theo đó, số Re thấp thì ảnh hưởng của độ nhớt có vai trò quan trọng hơn tác động của lực quán tính, chất lỏng chảy thành tầng. Trong trường hợp này, chất lỏng chảy thành các lớp song song, quá trình chuyển khổi trong chất lỏng chỉ có thể xảy ra theo hướng dòng chảy và sự pha trộn giữa các lớp chất lỏng chủ yếu là sự khuếch tán phân tử. Ngược lại, chỉ số Re cao thì dòng chảy bị chi phối bởi lực quán tính, các lớp chất lỏng chuyển động theo các phương khác nhau, dòng chảy trở nên hỗn loạn. Trong các hệ thống vi dòng chảy, số Re thường thấp hơn 100 và do đó dòng chảy được coi là các lớp song song. Đặc tính của dòng chảy chất lỏng có ảnh hưởng trực tiếp đến việc trộn trong các thiết bị vi dòng chảy, với dòng chảy tầng thì sự pha trộn giữa các lớp chất lỏng bị chi phối chủ yếu bởi sự khuếch tán phân tử $[3,4]$.

Các vi kênh được tạo ra bằng cách đúc hoặc khắc từ các vật liệu như silic, thủy tinh, hoặc polymer nhu poly(dimethyl siloxane) (PDMS), poly(methyl methacrylate) (PMMA),... Trong những năm gần đây, polymer dần trở thành nguồn vật liệu cơ bản cho các chip vi lưu. Polymer được ưa chuộng hơn cả là PDMS do chi phí thấp, đặc tính dễ dàng tạo khuôn, tạo kiểu để hình thành vi kênh, dễ tạo ra các chi tiết kích cỡ micromet với độ chính xác cao, trong suốt, độ ổn định hóa học cao, không độc hại. Tuy nhiên nhược điểm lớn nhất của PDMS trong tổng hợp các tiểu phân nano mang thuốc là khả năng chịu được dung môi hữu cơ của PDMS kém. Nó có thể bị trương lên khi tương tác với dung môi như là hydrocacbon thơm, hay ngay cả với dung dịch amin và acid mạnh $[5,6]$. Khắc phục nhược điểm này, một số nguyên liệu đang được xem xét sử dụng gần đây, điển hình như PMMA với những ưu điểm chi phí thấp, dễ dàng chế tạo, độ bền cơ học cao, đặc tính quang học rất tốt, không bị ảnh hưởng bởi hầu hết các dung dịch hóa chất như chất tẩy rửa, chất làm sạch, các dung dịch acid hay kiềm và các hợp chất hydrocarbon béo, tuy nhiên các tính chất cơ học của PMMA lại bị thay đổi theo nhiệt độ [5-8].

Các chip vi lưu đơn giản nhất hiện nay bao gồm các vi kênh được tạo khuôn trong một khối polymer được gắn với một mặt phẳng. Một số cấu tạo hình học đơn giản của chip hay được sử dụng là cấu trúc chữ $\mathrm{T}$, chữ $\mathrm{Y}$ hay cấu trúc chữ thập (Hình 1). Sự khác nhau về hình dạng hình học của chip sẽ quy định cơ chế tương tác giữa các dòng chất lỏng, từ đó ảnh hưởng đến hình dạng và kích thước các tiểu phân tạo thành [5].

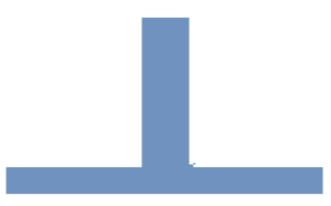

(A)

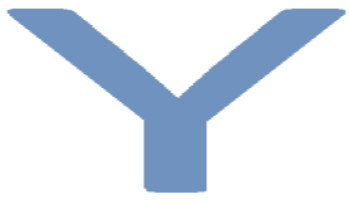

(B)

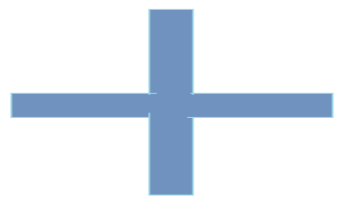

(C)

Hình 1. Một số dạng cấu tạo hình học đơn giản của chip hay được sử dụng: 1A- Cấu trúc chữ T;

1B- Cấu trúc chữ Y; 1C- Cấu trúc chữ thập.

Trong chip vi lưu, chất lỏng được tiêm vào hay dẫn ra ngoài thông qua các lỗ nhỏ gọi là đầu vào (inlet) và đầu ra (outlet) (Hình 2). Hệ thống này được tích hợp với hệ thống bên ngoài để đẩy dòng chảy một cách chủ động như bơm xilanh, bơm nhu động, thiết bị điều khiển áp suất [2].

Phân loại: Có 2 hệ thống vi dòng chảy thường được sử dụng để bào chể tiểu phân nano, 
gồm hệ thống vi dòng chảy tập trung (Micro hydrodynamic focussing (MHF)), thường dùng để bào chế liposome có kích thước nano và hệ thống vi dòng chảy nhỏ giọt (Microfluidic droplets) thường dùng bào chế liposome có kích thước lớn (đường kính lớn hơn 10 micromet) $[9,10]$.

Hệ thống vi dòng chảy tập trung (MHF): Đây là kỹ thuật vi dòng chảy được nghiên cứu rộng rãi nhất, tạo ra các sản phẩm liposome với sự kiểm soát tinh vi về kích thước. Nguyên tắc: dung dịch đệm (pha nước) chảy dọc từ hai phía đối diện của một kênh hình chữ nhật, trong khi dung dịch phospholipid trong isopropyl alcol chảy giữa các lớp nước dọc theo trục của kênh (Hình 3). Trong mô hình này, pha trộn giữa dung dịch phospholipid trong alcol và dung dịch nước được xảy ra trong vi kênh. Sự hòa tan nước và alcol vào nhau làm giảm nồng độ dung môi alcol dẫn đến tự sắp xếp phospholipid thành các chuỗi lớp kép cuối cùng đóng thành liposome.

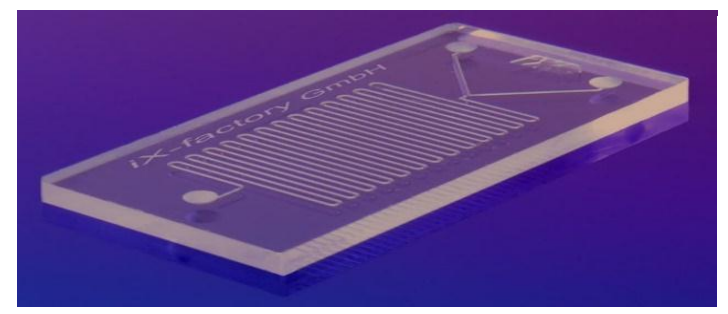

(A)

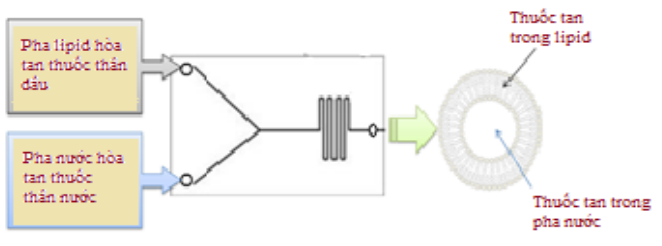

(B)

Hình 2. (A) Hình ảnh 1 chip vi lưu; (B) Sơ đồ hoạt động để bào chê liposome: pha lipid và pha nước được đưa vào 2 đầu vào (inlet). Các pha được tương tác dọc theo chiều dài kênh hình thành liposome, dòng liposome được đưa ra khỏi kênh [2].

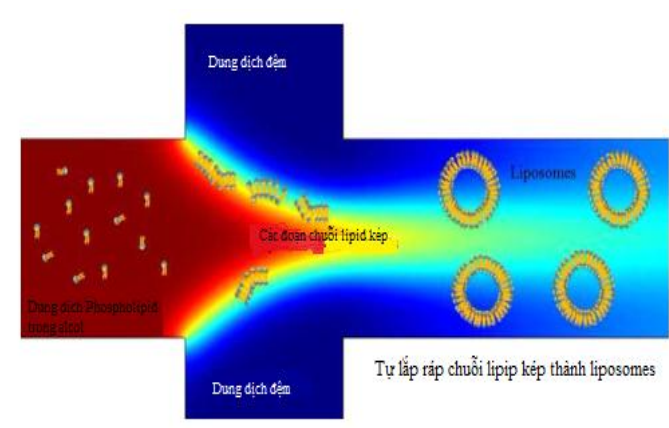

(A)

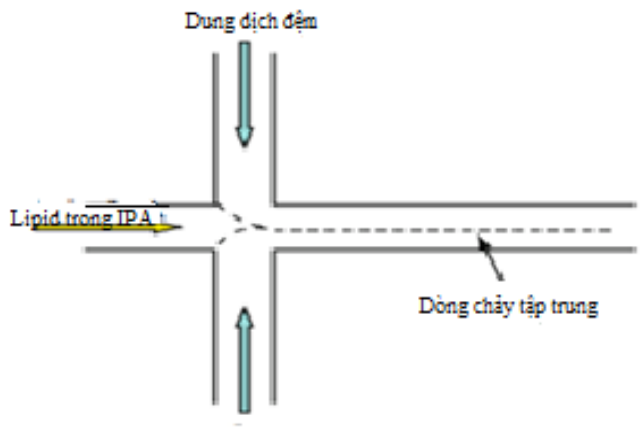

Dung dịch đẹm
(B)

Hình 3. Sơ đồ hình thành liposome trong dòng chảy tập trung [9].

A- Mô hình hình thành liposome; B- Mô hình kênh vi dòng chảy.

Hệ thống vi dòng chảy nhỏ giọt: Nguyên tắc (Hình 4): Sử dụng thiết bị vi dòng chảy để tạo nhũ tương $\mathrm{N} / \mathrm{D} / \mathrm{N}$ được điều chế bằng cách tạo ra các giọt $\mathrm{N} / \mathrm{D}$ và sau đó đóng gói lại chúng trong nước. Các lớp đơn phospholipid được xếp tại bề mặt phân cách pha dầu và nước. Khi bốc hơi pha dầu, các lớp đơn hòa trộn để tạo thành lớp kép của liposome có đường kính trung bình trong khoảng 4-20 micromet [9].

Úng dụng: Công nghệ vi dòng chảy được ứng dụng trong nhiều lĩnh vực $[5,10,11]$. Trong lĩnh vực y sinh học, công nghệ vi dòng chảy cho phép phân tích nhiều xét nghiệm y tế trên 1 chip 
duy nhất với lượng mẫu thử nhỏ, như xét nghiệm acid nucleic; chế tạo các hạt có kích thước cỡ micromet và nanomet, ứng dụng làm hệ mang thuốc, tạo nên các dạng bào chế có sinh khả dụng cao, tác dụng tại đích như liposome. Trong nghiên cứu sinh học tế bào, các vi kênh có kích thước tương tự các tế bào sinh học, do đó chip vi dòng chảy cho phép thao tác dễ dàng trên các tế bào đơn lẻ. Đồng thời công nghệ cũng được ứng dụng trên nhiều lĩnh vực khác như công nghệ vi phản ứng điện hóa học, làm mát bộ vi xử lí,..
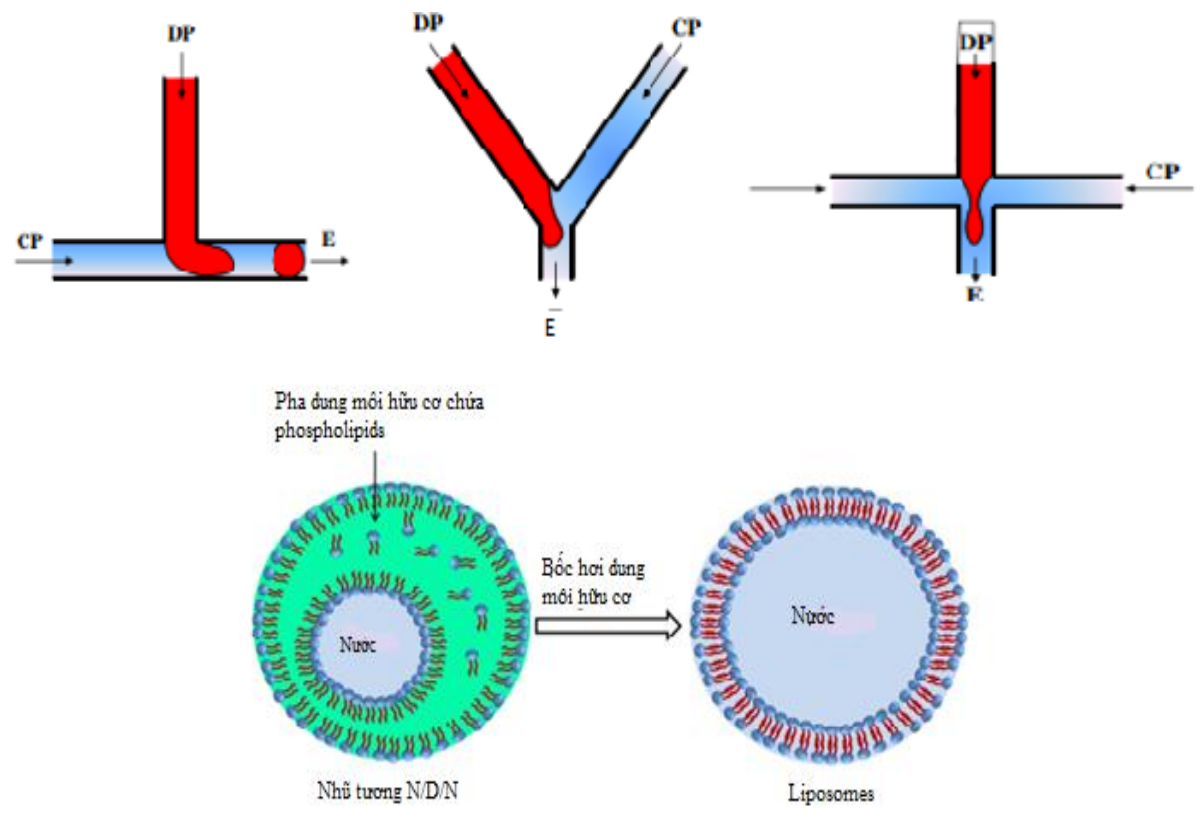

Hình 4. Một số mô hình đơn giản sử dụng trong hệ thống dòng chảy nhỏ giọt.

(DP: pha phân tán, CP: môi trường phân tán, E:nhũ tương) [9].

\section{2. Úng dụng công nghệ vi dòng chảy để bào chế một số tiểu phân nano mang thuốc}

\subsection{Bào chế tiểu phân liposome}

Trong vài thập kỷ gần đây, liposome đã thu hút được sự quan tâm lớn. Với cấu tạo tương tự màng sinh học, liposome là một hệ mang thuốc hiệu quả, tác dụng tại đích, nâng cao sinh khả dụng và hạn chế tác dụng không mong muốn của thuốc $[12,13]$. Một số phương pháp đã được phát triển để bào chế liposome, chẳng hạn như hydrat hóa phim, tiêm ethanol, bốc hơi pha đảo. Tuy nhiên, việc bào chế liposome bằng các phương pháp này thường khó đồng nhất lô mẻ. Do vậy, liposome tiếp đó sẽ được xử lí bằng cách đùn, siêu âm, hoặc đồng nhất ở áp suất cao để thu được kích thước và khoảng phân bố kích thước theo yêu cầu $[9,10,14]$. Vi dòng chảy là một công nghệ vận dụng sự chuyển động của dòng chất lỏng trong các vi kênh, tạo ra một quá trình hòa trộn nhanh và có kiểm soát, một môi trường phản ứng đồng nhất. Do đó, nó là một công nghệ hấp dẫn cho nhiều ứng dụng trong tổng hợp hóa học và phân tích sinh học. Việc kiểm soát tinh tế của dòng chảy và điều kiện trộn trong vi kênh đã được áp dụng để làm thay đổi kích thước và cải tiến tính đồng nhất kích thước hạt. Cách phát triển phương pháp vi dòng chảy để điều khiển sự hình thành liposome là một phương pháp mới đầy tiềm năng để bào chế liposome với chất lượng được kiểm soát dễ dàng hơn [3, 10, 14].

Một số nghiên cứu sử dụng công nghệ vi dòng chảy để điều chế liposome:

S. Joshi và cộng sự (2016) nghiên cứu bào chế liposome đóng gói đồng thời tiểu phân thuốc thân nước và kị nước [15]. Chuẩn bị dược chất 
là Metformin $\mathrm{HCl}$ và Glipizide. Pha nước gồm Metformin. $\mathrm{HCl}$ hòa tan trong dung dịch đệm, pha lipid gồm Glipizide và các phospholipid hòa tan trong alcol (methanol hoặc ethanol). Thiết bị vi dòng chảy với cấu trúc tương tác SHM (Staggered Herringbone Micromixer) như hình 5 được sử dụng để bào chế liposome. Phương pháp dòng chảy tập trung với tỉ số giữa 2 pha nước và pha lipid được thay đổi từ $5: 1$ đến $1: 1$ và tổng tốc độ dòng từ 5 đến $15 \mathrm{~mL} /$ phút. Kết quả cho thấy, tại mọi TFR, khi FRR là 1: 1 có khuynh hướng tạo ra các liposome lớn nhất, kích thước khoảng 200-300 nm với giá trị PDI từ 0,38-0,67. Khi tăng FRR tới 3:1, kích cỡ của liposome giảm đến khoảng 120-130 nm và khi tăng đến tỉ lệ 5 : 1 , kích thước đến giảm 80-90 nm với PDI khoảng $0,11-0,22$. Kết luận rằng TFR không có ảnh hưởng đáng kể đến kích thước liposome, trong khi đó FRR lại có ảnh hưởng quan trọng đến kích thước tiểu phân.

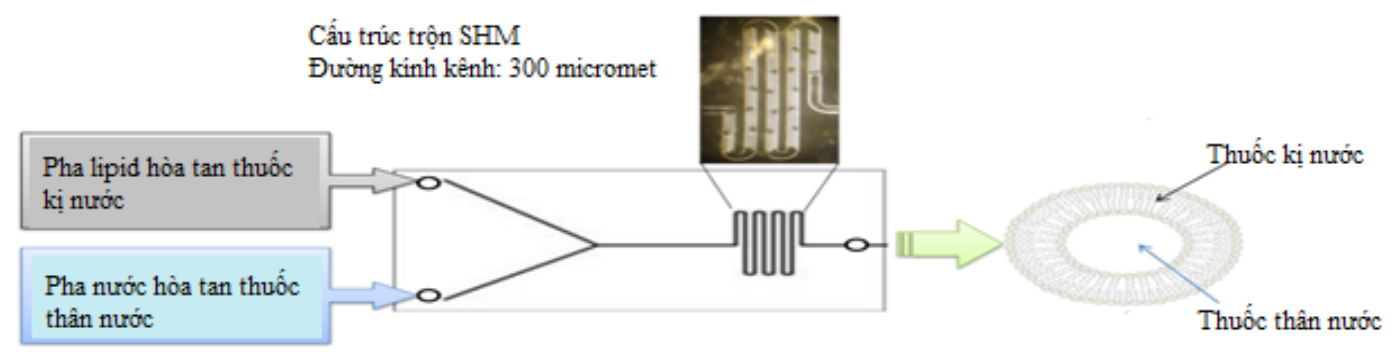

Hình 5. Liposome được bào chế bằng thiết bị vi dòng chảy [15].

Koh và cộng sự (2009) bào chế liposome chứa Oligonucleotides bằng phương pháp $\mathrm{MHF}$. Oligonucleotides (ONs), bao gồm cả các oligodeoxynucleotides antisense (AS-ODN) và siRNA, đang được chú ý ứng dụng như một liệu pháp điều trị nhiều bệnh [16-18]. Tuy nhiên, việc sử dụng Oligonucleotides trong điều trị bệnh vẫn còn rất hạn chế do việc thiếu các hệ phân phối an toàn và hiệu quả. Để khắc phục điểu này, một số nghiên cứu đã hướng đến bào chế liposome chứa Oligonucleotides. Để bào chế liposome đồng nhất và phân bố kích thước hẹp, các tác giả đã tiến hành phát triển công nghệ bào chế sử dụng thiết bị vi dòng chảy làm từ PMMA gồm năm cổng vào (inlet) và một cổng ra (outlet). Các cổng đầu vào được nối với các ống tiêm vô trùng có chứa dung dịch lipid trong ethanol, protamine hoặc dung dịch $\mathrm{ON}$ được dẫn vào kênh và liposome thu được tại đầu ra. Điều chỉnh tỉ số tốc độ dòng $(F R R)$ của 2 dòng lipid và protamine từ hai kênh bên đến dòng trung tâm (dung dịch $\mathrm{ON}$ ) . Tốc độ chảy của các dòng $\mathrm{ON}$, protamine và dòng lipid lần lượt là 20 và $450 \mu \mathrm{l} /$ phút. Kết quả thu được các nano liposome kích thước nhỏ $(114,8 \pm 12,7 \mathrm{~nm})(\mathrm{PDI}=0,120 \pm 0,063)$ so với liposome $\mathrm{G} 3139$ bào chế bởi $\mathrm{BM}(152,7 \pm 22,1$ $\mathrm{nm})(\mathrm{PDI}=0,121 \pm 0,052)[18]$.

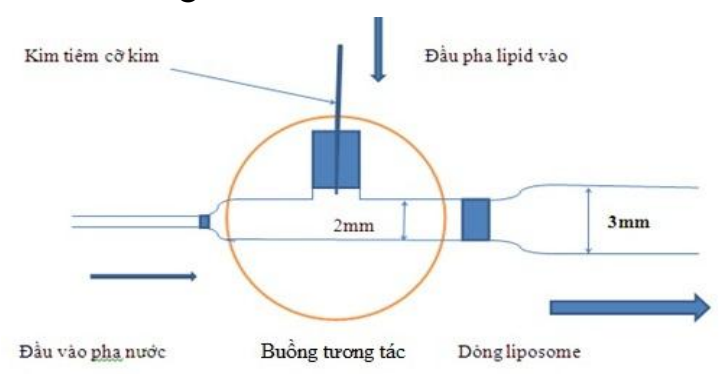

Hình 6. Sơ đồ thiết bị bào chế liposome Indomethacin bằng kỹ thuật vi dòng chảy. 
Tại Việt Nam, việc ứng dụng công nghệ vi dòng chảy để bào chế liposome vẫn còn rất hạn chế, cho tới những năm gần đây kĩ thuật này mới bắt đầu được chú ý đến. Trần Thị Hải Yến và cộng sự (2016) đã tiến hành bào chế liposome indomethacin bằng hệ thống vi dòng chảy tập trung. Góc tương tác giữa hai pha lipid và pha nước được thiết kế là $90^{\circ}$ để hạn chế hiện tượng đẩy ngược dòng (Hình 6) [19]. Pha nước và pha lipid được bơm vào buồng tương tác thông qua các kim tiêm nhờ hai máy bơm nhu động. Khảo sát các thông số dòng chảy, kết quả cho thấy rằng tại khoảng FRR không ảnh hưởng đến KTTP và PDI thì TFR cũng không ảnh hưởng, còn ở khoảng FRR còn ảnh hưởng đến KTTP và PDI thì TFR cũng ảnh hưởng.

\subsection{Bào chế tiểu phân nano polyme (polymer nanoparticles- PNPS)}

Trong những năm gần đây, các tiểu phân nano polymer nhận được sự quan tâm đáng kể với tiềm năng ứng dụng trong phạm vi rộng như chẩn đoán và phân phối thuốc. Uu điểm của PNPs là khả năng giải phóng có kiểm soát, bảo vệ các phân tử thuốc và tác dụng tại đích, tạo điều kiện nâng cao chỉ số điều trị $[20,21]$. Các tiểu phân nano polymer có thể có cấu trúc vi nang (nanocapsules) hay vi cầu (nanospheres) (Hình 7). Với cấu trúc vi nang, NPs có hình thái lõi-vỏ với một khoang chứa nước hoặc dầu, trong đó thuốc được giới hạn và được bao quanh bởi một lớp vỏ polymer. Với cấu trúc vi cầu, NPs là tiểu phân cầu trong đó thuốc và các polymer được phân tán đồng đều [22, 23].

Qua nhiều năm, một loạt các polyme tổng hợp đã được khám phá để bào chế các hạt nano mang thuốc (nanoparticles- NPs). Các polyme nhu Poly (lacticco-glycolic acid) (PLGA), poly (lactic Acid), poly (methyl methacrylate) (PMMA) và Pluronic F-127 đã thu được sự chú ý đặc biệt nhờ vào khả năng tương hợp và phân hủy sinh học. PLGA là một trong những polyme sử dụng phổ biến và rộng rãi nhất bởi các tính chất độc đáo, không độc hại, sự phù hợp về sinh học và được tổ chức Quản lý Thực phẩm và Dược phẩm Hoa Kì (FDA) phê duyệt an toàn cho người sử dụng [21, 24, 25].
So với các phương pháp truyền thống, công nghệ vi dòng chảy cho phép bào chế có kiểm soát và đồng nhất lô mẻ. Hai loại phương pháp đã được phát triển để tổng hợp PLGA NPs là dòng chảy tập trung và nhỏ giọt [25-27].

Một số nghiên cứu sử dụng công nghệ vi dòng chảy để bào chế tiểu phân nano polymer:

Sun và cộng sự (2013) đã nghiên cứu các chip vi dòng chảy với những cấu trúc hình học khác nhau để bào chế Doxorubicin nạp trong PLGA NPs với kích thước có thể điều chỉnh được (70-230 nm) trong một bước trộn nhanh và có kiểm soát PLGA-Dox với nước [28]. Phương pháp dòng chảy tập trung với các chip được chế tạo bằng PDMS với các dạng hình học khác nhau. Dung dịch PLGA-Dox 2\% được pha loãng bởi dòng chảy liên tục (nước hoặc đệm) trong chip vi dòng chảy, kết quả tạo ra NPs. Thiết kế đạt được năng suất 1200 mg NPs mỗi ngày với tốc độ dòng chảy tối đa $2,5 \mathrm{~mL} / \mathrm{h}$ đối với dung dịch PLGA-Dox 2\% (Hình 7).

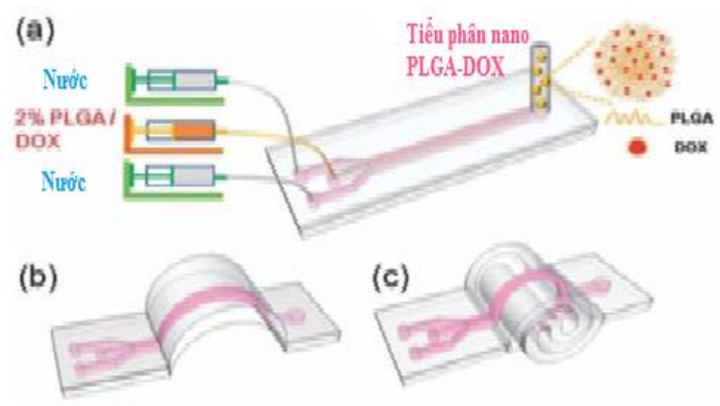

Hình 7. Các chip với dạng hình học khác nhau để bào chế PLGA-Dox NPs.

(a) Cấu tạo mặt phẳng (b) Cấu tạo vòng cung (c) Cấu tạo xoắn ốc [28] Karnik và cộng sự (2008) bào chế Docetaxel (Dtxl) nạp trong poly (acid lactic-co-glycolic)-b-poly (ethylene glycol) (PLGA-PEG) NPs bằng cách sử dụng thiết bị vi dòng chảy $2 \mathrm{D}$ dòng chảy tập trung (2D hydrodynamic flow focusing (HFF)) [29]. Tiến hành thay đổi tốc độ dòng chảy, thành phần polyme và nồng độ polyme, thu được các NPs có kích thước nhỏ, phân bố kích thước tiểu phân hẹp, hiệu suất tải thuốc cao với sự phóng thích 
dược chất chậm hơn. Tuy nhiên, một trong những thách thức của việc sử dụng $2 \mathrm{D}$ HFF là các NPs có xu hướng tập hợp lại, do đó làm tắc nghẽn kênh. Rhee và cộng sự (2011) thiết kế thiết bị 3D HFF khắc phục được những nhược điểm trên và thu được các chế phẩm đồng nhất về lô mẻ [30]. Lim và cộng sự (2014) phát triển một thiết bị 3D HFF nâng cấp quy mô bằng cách tăng số lượng tương tác cho phép tổng hợp NPs với tốc độ bào chế có thể tăng lên đáng kể. Cụ thể khi sử dụng kết hợp 8 thiết bị HFF $3 \mathrm{D}$ năng suất là $84 \mathrm{mg} / \mathrm{h}$ cao hơn đáng kể so với thiết bị HFF $3 \mathrm{D}$ đơn lẻ $4,5 \mathrm{mg} / \mathrm{h}$ ở điều kiện dòng chảy tương tự [31].

\subsection{Bào chế tiểu phân polymerosome}

Polymerosome (Ps) là loại túi được tạo ra một cách nhân tạo, cấu tạo là một túi được làm từ khối copolymer lưỡng thân, điển hình là những Ps hình cầu chứa lõi ưa nước được bao quanh bởi lớp màng kép. Lõi dung dịch nước có thể được sử dụng cho việc đóng gói các phân tử điều trị như thuốc, enzym, protein, peptide, DNA và RNA. Có thể tích hợp các loại thuốc kỵ nước trong lớp màng kỵ nước của polymerosome. Khả năng để nạp thuốc vào Ps đã có một số ứng dụng nổi bật trong y học, dược, và công nghệ sinh học với những ưu điểm Ps khá ổn định và có thời gian lưu thông dài trong máu [32-34].

Một số phương pháp đã được phát triển để bảo chế polymerosome, chẳng hạn như hydrat hóa phim, thay đổi dung môi. Tuy nhiên, việc bào chế polymerosome bằng các phương pháp này thường khó đồng nhất lô mẻ. Do đó, phương pháp vi dòng chảy đã được phát triển là một nền tảng mới để chế tạo polymersomes [35-37].

\section{3. Ưu nhược điểm của công nghệ vi dòng chảy trong bào chế tiểu phân nano mang thuốc}

$\boldsymbol{U} \boldsymbol{u}$ điểm: So với các phương pháp truyền thống để bào chế các tiểu phân nano mang thuốc, phương pháp vi dòng chảy có nhiều ưu điểm [3]: Đơn giản, tốn ít thời gian; tiểu phân nano thu được có kích thước đồng nhất, hiệu suất nạp thuốc cao; kiểm soát được các đặc tính của các tiểu phân thông qua việc kiểm soát các thông số như tốc độ dòng chảy, tỉ số tốc độ dòng của 2 pha,...; có thể nâng cấp quá trình thông qua tăng số lượng tương tác.

Nhực điểm: Thiết bị kích thước micromet không có sẵn, cần chế tạo tinh vi, giá thành cao.

\section{Nâng cấp quy mô với kĩ thuật vi dòng chảy}

Để có thể nâng cấp một quy trình bào chế thường khá phức tạp, nhìn chung thường trải qua 3 pha:

Pha 1: Thực hiện trên quy mô phòng thí nghiệm để có cái nhìn cụ thể về các tương tác động học, đặc tính chuyển khối, thông tin về thủy động lực học chất lỏng của quá trình. Các thông tin này là thiết yếu cho các nhà khoa học để hiểu được cơ chế của sự tương tác và sự hình thành đến sản phẩm để tối ưu hóa quá trình bào chế.

Pha 2: Đánh giá các thông số quy trình trong phòng thí nghiệm trong một vài quy mô lớn để tối ưu hóa quy trình.

Pha 3: Nâng cấp quy mô lên sản xuất lớn.

Tuy nhiên cách tiếp cận này có nhược điểm là những thay đổi về thể tích tương tác giữa các dòng chảy trong các giai đoạn khác nhau sẽ gây ra sự bất ổn định về đặc tính chuyển động khối và chuyển động nhiệt, gây ảnh hưởng xấu đến chất lượng của sản phẩm khi áp dụng với quy mô lớn [38].

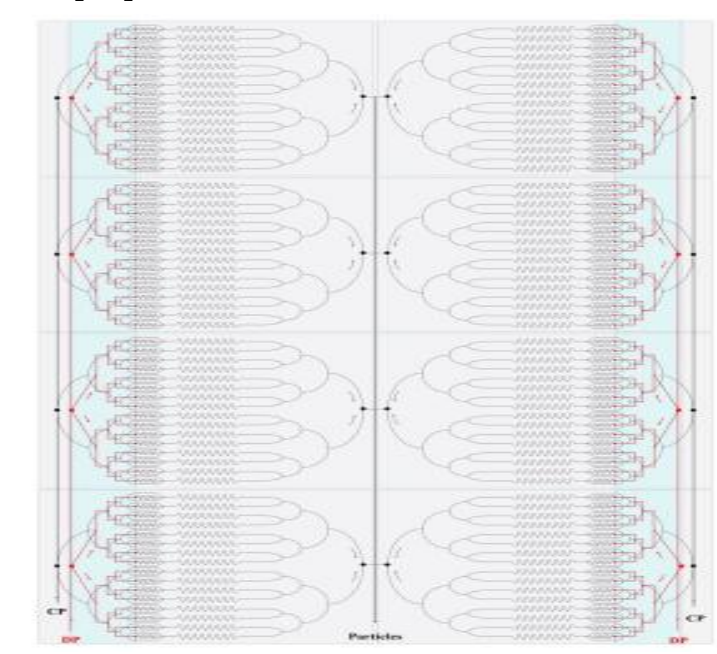

Hình 9. Nâng cấp quy mô thiết bị vi dòng chảy bằng tăng số lượng các tương tác [5]. 
Có hai hướng để nâng cấp quy mô với thiết bị vi kênh. Một là tăng tốc độ dòng [39], tăng kích thước thiết bị [38], hai là tăng số lượng các tương tác $[5,39]$. So với hướng thứ nhất thì hướng thứ hai có ưu điểm là các quy trình tối ưu hóa được nghiên cứu trên quy mô phòng thí nghiệm sẽ được sử dụng và hạn chế được những khó khăn khi tăng kích thước thiết bị.

\section{Kết luận}

Những tiến bộ trong công nghệ nano đã cho thấy sự cần thiết phải phát triển những phương pháp bào chế hiệu quả và có kiểm soát mang lại sự đồng nhất lô mẻ. Công nghệ vi dòng chảy vận dụng sự chuyển động của dòng chất lỏng trong các vi kênh, tạo ra một quá trình hòa trộn nhanh và có kiểm soát, một môi trường phản ứng đồng nhất. Do đó, nó là một công nghệ hấp dẫn cho nhiều ứng dụng trong tổng hợp hóa học và phân tích sinh học. Việc kiểm soát tinh tế của dòng chảy và điều kiện trộn trong vi kênh đã được áp dụng để làm thay đổi kích thước và cải tiến tính đồng nhất kích thước hạt. Cách phát triển phương pháp vi dòng chảy để điều khiển sự hình thành các tiểu phân nano mang thuốc là một phương pháp mới đầy tiềm năng để sản xuất các hạt nano với chất lượng được kiểm soát dễ dàng hơn.

\section{Tài liệu tham khảo}

[1] Nguyễn Thanh Hải, Bùi Thanh Tùng, Phạm Thị Minh Huệ, Phỏng sinh học trong y dược học Hướng nghiên cứu cần đẩy mạnh, Tạp chí Khoa học ĐHQGHN, Khoa học Y Dược. 33(1) (2017) 1-4. https://doi.org/10.25073/2588-1132/vnumps.4070.

[2] Plug \& Play Microfluidics. http://www.elveflow.com (truy cập ngày 05/08/2017).

[3] L.Capretto, D. Carugo, S. Mazzitelli et al., Microfluidic and lab-on-a-chip preparation routes for organic nanoparticles and vesicular systems fornanomedicine applications, Advanced Drug Delivery Reviews. 65(11-12) (2013) 1496-1532. https://doi.org/10.1016/j.addr.2013.08.002.

[4] Renolds number. https://neutrium.net/fluid_flow/reynolds-number/ (truy cập ngày 05/08/2017).
[5] G.T. Vladisavljević et al., Industrial lab-on-a-chip: Design, applications and scale-up for drug discovery and delivery, Advanced Drug Delivery Reviews. 65(11-12) (2013) 1626-1663.

[6] J.C. McDonald and G.M. Whitesides. Poly (dimethylsiloxane) as a Material for Fabricating Microfluidic Devices, Accounts of Chemical Research. 35 (2002) 491-499.

[7] K. Ren, J. Zhou, H. Wu, Materials for Microfluidic Chip Fabrication, Accounts of chemical research. 46 (11) (2013) 2396-2406.

[8] Y.Chen, L. Zang, G. Chen. Fabrication, modification, and application of poly (methyl methacrylate) microfluidic chips, Electrophoresis. 29 (2008) 1801-1814.

[9] Y.P. Patil, S. Jadhav. Novel methods for liposome preparation, Chemistry and Physics of Lipids. 177 (2014) 8-18.

[10] B. Yu et al. Microfluidic Methods for Production of Liposomes, Methods in Enzymology. 465 (2009) 129-141.

[11] D.B.Weibel and G.M.Whitesides. Applications of microfluidics in chemical biology, Current Opinion in Chemical Biology. 10(6) (2006) 584-591.

[12] Trần Thị Hải Yến. Liposome - hệ vận chuyển thuốc tiên tiến trong công nghệ dược phẩm, Tạp chí dược và thông tin thuốc. 4(4) (2013) 146-152.

[13] T.M. Allen, P.R.Cullis. Liposomal drug delivery systems: From concept to clinical applications, Advanced Drug Delivery Reviews. 65(1) (2012) 36-48. https://doi.org/10.1016/j.addr.2012.09.037.

[14] D. Carugo, E. Botaro, J. Owen et al., Liposome production by microfluidics: potential and limiting factors, Nature Scientific Reports. 6(1) (2016) 25876.

[15] S. Joshi, T.H. Mariam, B.R. Carla et al., Microfluidics based manufacture of liposomes simultaneously entrapping hydrophilic and lipophilic drugs, International Journal of Pharmaceutics. 514(1) (2016) 160-168. https://doi.org/10.1016/j.ijpharm.2016.09.027.

[16] D.M. Dykxhoorn and J.Lieberman. Knocking down disease with siRNAs, Cell, 126 (2006) 231-235.

[17] J. Kurreck. Antisense technologies. Improvement through novel chemical modifications, Eur. J. Biochem, 270 (2003) 1628-1644.

[18] C.G. Koh, X. Zhang, S. Liu et al. Delivery of antisense oligodeoxyribonucleotide lipopolyplex nanoparticles assembled by microfluidic hydrodynamic focusing, Journal of Controlled Release. 141 (2009) 62-69.

[19] Trần Thị Hải Yến, Vũ Thị Hương, Phạm Thị Minh Huệ, Bào chế liposome indomethacin bằng phương 
pháp vi dòng chảy, Tạp chí Dược và Thông tin thuốc. 7(4-5) (2016) 36-40.

[20] K.M.El-Say and H.S. El-Sawy. Polymeric nanoparticles: Promising platform for drug delivery, International Journal of Pharmaceutics. 528(1-2) (2017) 675-691.

[21] A. Kumari, S.K. Yadav, S.C. Yadav et al., Biodegradable polymeric nanoparticles based drug delivery systems, Colloids and Surfaces B: Biointerfaces. 75(1) (2010) 1-18.

[22] I.C. Crucho, M.T. Barros. Polymeric nanoparticles: A study on the preparation variables and characterization methods, Materials Science and $\begin{array}{llll}\text { Engineering. } & 80 & \text { (2017) } & \text { 771-784. }\end{array}$ https://doi.org/10.1016/j.msec.2017.06.004

[23] Phạm Thị Minh Huệ, Nguyễn Thanh Hải. Liposome, phytosome- Phỏng sinh học trong bào chế, nhà xuất bản Đại học Quốc gia Hà Nội, 2017.

[24] T. Baby, L. Yun, P.J. Midleberg et.al., Fundamental studies on throughput capacities of hydrodynamic flow-focusing microfluidics for producing monodisperse polymer nanoparticles, Chemical Engineering Science. 169 (2017) 128139. https://doi.org/10.1016/j.ces.2017.04.046Get rights and content.

[25] H.K. Makadia and S.J. Siegel. Poly Lactic-coGlycolic Acid (PLGA) as Biodegradable Controlled Drug Delivery Carrier, Polymers, 3, (2011) 1377-1397.

[26] P. Baipaywad, N. Venkatesan, B.V. Betavegi. Size-Controlled Synthesis, Characterization, and Cytotoxicity Study of Monodisperse Poly(dimethylsiloxane) Nanoparticles', Journal of Industrial and Engineering Chemistry. 53 (2017) 177-182. https://doi.org/10.1016/j.jiec.2017.04.023.

[27] R.Ran, Q. Sun, T. Baby et al., Multiphase microfluidic synthesis of micro- and nanostructures. for pharmaceutical applications, Chemical Engineering Science. 169 (2017) 78-96. https://doi.org/10.1016/j.ces.2017.01.008.

[28] J.Sun, Y. Xiangnuy, M. Li et al., A microfluidic origami chip for synthesis of functionalized polymeric nanoparticles, Nanoscale. 5 (2013) 5262-5265.
[29] R. Karnik, F. Gu, P. Basto et al., Microfluidic platform for controlled synthesis of polymeric Nanoparticles, Nano Lett. 8 (2008) 2906-2912.

[30] M.Rhee, P.M. Valencia, M.I. Rodrigues et.al. Synthesis of size-tunable polymeric nanoparticles enabled by 3D hydrodynamic flow focusing in single-layer microchannels, Adv. Mater. 23 (2011) H79-H83.

[31] J.M. Lim, N. Bertrand, P.M. Valencia et.al., Parallel microfluidic synthesis of size-tunable polymeric nanoparticles using 3D flow focusing towards in vivo study, Nanomedicine: Nanotechnology, Biology and Medicine. 10 (2014) 401-409.

[32] M.Mohammadi, R. Mohamad, A, Khalil et al., Biocompatible Polymersomes-based Cancer Theranostics: Towards Multifunctional Nanomedicine, International Journal of Pharmaceutics. 519(1-2) (2017) 287-303. https://doi.org/10.1016/j.ijpharm.2017.01.037.

[33] H.Y.Chang, Y.J.Sheng, H.K.Tsao. Structural and mechanical characteristics of Polymersomes, Soft Matter. 10 (2014) 6373-6381.

[34] R. Rastogi, S. Anard, V. Koul. Flexible polymerosomes-An alternative vehicle for topical delivery, Colloids and Surfaces B: Biointerfaces, 72(1) (2009) 161-166. https://doi.org/10.1016/j.colsurfb.2009.03.022.

[35] L. Brown, S.L. McAthur, P.C. Wright et al., Polymersome production on a microfluidic platform using $\mathrm{pH}$ sensitive block copolymers, The Royal Society of Chemistry. 10 (2010) 1922-1928.

[36] J.S. Lee, J. Feijen. Polymersomes for drug delivery: Design, formation and characterization, Journal of Controlled Release. 161(2) (2012) 473-483.

[37] J. Thiele, D. Steimhauser, T. Pfohl et al., Preparation of Monodisperse Block Copolymer Vesicles via Flow Focusing in Microfluidics, Langmuir. 26(9) (2010) 6860-6863.

[38] P.R. Makgwane and S.S. Ray. Synthesis of Nanomaterials by Continuous-Flow Microfluidics: A Review, Journal of Nanoscience and Nanotechnology. 14(2) (2014) 1338-1363.

[39] M. Lu, A. Ozcelic, C.L. Grigsby et al., Microfluidic hydrodynamic focusing for synthesis of nanomaterials, Nano Today. 11(6) (2016) 778-792. https://doi.org/10.1016/j.nantod.2016.10.006. 